\title{
NOTAS BREVES
}

\section{DELIBERANDO SOBRE OS INCENTIVOS SANITARIOS NA ÁREA DA ÉTICA PARA OS EFECTOS DA CONSTRUCIÓN DUN PLAN DE INCENTIVOS NO SISTEMA PÚBLICO \\ SANITARIO \\ Maria Jesus CASTRO GIGIREY \\ Técnico Superior de Xestión, SERGAS \\ Fundación Pública Instituto Galego de Oftalmoloxía mariacgigirey@gmail.com}

Os programas de pago por obxectivos ou de pago por rendemento son unha práctica habitual do noso sistema de saúde, pero a actual crise e o conseguinte aumento de control do gasto público, sobre todo no eido sanitario, produciu unha grande incerteza sobre o beneficio dos devanditos pagos, máxime cando o gasto sanitario representa case o $30 \%$ do gasto público e dentro deste, a partida de custo de persoal, á que apuntamos directamente cos incentivos, é das máis altas. Entón, está ou non xustificado o pago de incentivos no sistema sanitario dende o punto de vista ético, económico, social e/ ou laboral?

Malia que un sistema sanitario é un sistema "peculiar" por tratar un tema tan delicado como "a saúde", falamos dun sistema con carácter de lucro dende o momento en que é retribuído o traballo de cada elemento. Outra cousa é que o obxectivo primordial do traballador deste sistema sanitario non deba ser o diñeiro, e que na procura dunha excelencia colectiva, cada traballador como profesional deba ter un compromiso persoal co mesmo.

O establecemento dun plan de incentivos simplificaríase se partísemos dun escenario idílico onde a ética, a honestidade e a profesionalidade son respectados, e a partir daí, procurásemos fórmulas que favorecesen tanto a contorna laboral como a profesional e a sectorial. Pero todos sabemos que o escenario actual e real, por desgraza, non é este e adoece de grandes defectos e numerosos inconvenientes que agora non imos detallar, pero que dificultan o desenvolvemento dun plan de incentivos que provoque realmente 0 incremento da produtividade, a mellora do sistema e a satisfacción do paciente e da sociedade.

Unha vez coñecidas as características e o eido do sistema no que queremos instituír ou deseñar ese plan de incentivos, debemos coñecer as características que deben ter eses incentivos para acadar o mellor resultado posible tanto para os elementos do sistema como para o sistema en si mesmo.

Os incentivos empréganse de maneira xeneralizada en case todas as organizacións tanto públicas como privadas e en case todos os contextos laborais. Poden ser de tipo individual ou colectivo, dirixidos a equipos internos concretos ou a organizacións en xeral. Mesmo poden ser positivos ou negativos, financeiros ou non financeiros, tanxibles ou intanxibles, ...

En todo caso, para que os incentivos cumpran a súa verdadeira función nun sistema empresarial, extrapolado a un sistema sanitario, deben cumprir as seguintes características:

- O incentivo debe ser bidireccional, é dicir, debe ser positivo para o traballador e para o sistema. 
- Non poden ser incentivos deseñados e aplicados a curto prazo. Requiren un tempo de deseño, establecemento e, sobre todo, análise e revisión. Deben ser axeitados, estratéxicos e cunha finalidade clara e real.

- Deben ser coñecidos e accesibles a todos os traballadores, baseados en principios de publicidade, transparencia, equidade e coherencia. O deseño debe incluír uns obxectivos claros e realistas pois de nada servirá formular uns obxectivos imposibles de acadar por moita rendibilidade e eficacia que impliquen para 0 sistema.

- Debemos avaliar a propia natureza do incentivo e a súa participación e aceptación na comunidade e no sistema. E para iso é absolutamente necesario que sexan sustetibles de medición e avaliación de acordo co obxectivo que pretendan. Como consecuencia, deben incorporar reaxustes automáticos no caso de que as medicións non sexan as esperadas sobre a base da efectividade, os resultados numéricos formulados, a seguridade, a calidade, etc.

- Deben procurar a motivación do empregado a ser o máis produtivo posible.

- Esta é unha das características máis importantes dos incentivos no eido sanitario e é que deben procurar reter o Know-how valioso dentro do sistema asemade que consiga desalentar aos trabajadores non produtivos a non acadar os devanditos incentivos. Hongoro e Norman citan nun dos seus estudos (2006) que "alomenos a metade da variación da rotación dos $\mathrm{RRHH}$ pódese atribuír aos incentivos financeiros".

- O seu establecemento debe atraer o mellor persoal dispoñible no mercado, polo tanto debe ser suficientemente atraente.

- Sería desexable que ademais consiga equilibrar o maior aforro posible en cargas sociais, seguros, pensións, etc.

Partamos, polo tanto, da base de que as características dos incentivos e dos plans de incentivos, deben ser idénticas.

A fase de deseño dun plan de incentivos equilibrado, xusto e sostido require tempo, e necesita que o incentivo sexa unha ferramenta ou un estímulo para acadar determinados obxectivos ben definidos, pero que nunca se converta nun fin en si mesmo pois, do contrario, o mesmo incentivo transformaríase automaticamente nun acto perverso. É dicir, o incentivo e con iso o plan, deben seguir un propósito lexítimo e no momento no que non o fagan, perderán a súa propia lexitimidade.

Os deseños máis acertados sempre son os "traxes a medida", é dicir, os conxuntos de incentivos que máis se adapten ao contexto ao que van ser aplicados, o que fai que non exista un único método nin un único modelo que satisfaga as necesidades nin de todas as organizacións nin de todos os profesionais. Débese procurar por tanto un claro equilibrio entre a individualidade das diferenzas e a adaptabilidade sistemática aos cambios e aos diferentes contextos colectivos, o que vén sumar outra dificultade ao deseño.

Dentro do plan de deseño e sobre todo ao falar de sistema sanitario público, hai unha característica que debemos valorar coidadosamente e é a procedencia do incentivo. É dicir, se provén directamente do propio sistema, ou de axentes externos permitidos por un sistema público. Teñamos especial coidado na procedencia dende eses axentes externos, sexan provedores ou outro tipo de empresa privada, pois se perseguen ánimo de lucro dentro do noso sistema sanitario (así ocorre na meirande parte dos casos), a súa aportación ao funcionamento do programa de incentivos debe ser valorado e vixiado, para non entrar en conflito de intereses, competencia desleal, mecanismos encubertos de adquisición de produtos, etc. 
Entraríamos aquí moi directamente nos códigos da Federación Europea das Asociacións da Industria Farmacéutica e da Farma industria, entre outros.

Outro dos vértices do deseño dun plan de incentivos debe estar en diferenciar principalmente dous tipos de incentivos:

- os pactados ou acordados dentro do mesmo plan conforme ás características anteriores e nos que seguimos centrando o noso estudo.

- e os non pactados ou fóra do plan de incentivos que debemos considerar como ilícitos ou inmorais, é dicir, aqueles que se ofrecen fóra de todo pacto transparente como agasallos directos, pagos encubertos, etc. a algúns profesionais á marxe do equipo ou do grupo, pero que para o individuo en cuestión supón un acicate e unha valoración de compromiso de mellora.

Un apartado especial merecería que o plan de incentivos se poida formular tamén como un instrumento colectivo, orientado a promover as condicións que favorezan 0 crecemento e desenvolvemento sostible do propio sistema sanitario dende unha perspectiva colectiva ou de grupo incentivando aos equipos, aos colectivos e ao sistema como conxunto á mellora continua da xestión, e nunca ao individuo en si mesmo.

Esta idea non implica unha transferencia de recursos directa ás persoas senón aos grupos, aos equipos ou aos colectivos, polo cumprimento de certas metas ou obxectivos nun período determinado.

Neste deseño, todos os membros do equipo comparten beneficios ou recompensas asemade que son responsables solidarios do éxito ou do fracaso dos resultados.

Estes obxectivos, claramente deben ser formulados co fin único de impulsar resultados colectivos, cuxo logro require un traballo articulado e coordinado dos profesionais.

Así estaríamos falando de:

- Fortalecemento das capacidades dos equipos técnicos etc. mesmo a nivel formativo. Todos os membros do equipo son responsables dos resultados e con iso, fortalécese a axuda recíproca e as relacións positivas, non o beneficio individual.

- Mellora dos niveis de xestión e, polo tanto, de recursos, fortalecendo a estabilidade e eficiencia na percepción dos mesmos.

- Simplificación dos trámites entre os colectivos e o conxunto do sistema, xerando condicións favorables para o clima laboral, aproveitamento de sinerxías e promovendo a mellora do benestar social.

É por iso que moitos grupos de directivos ou de xestión se decantan polo establecemento de sistemas de incentivos grupais fronte aos individuais.

Neste momento e tendo en conta todo o anterior, estaríamos por fin no momento de deseñar un plan de incentivos eficaz seguindo as seguintes fases:

Fase 1) Determinar o obxectivo ou finalidade do plan.- É imprescindible partir do coñecemento exacto de para que deseñamos o plan, se seguiremos unha perspectiva colectiva ou individual, se o faremos dende un plano laboral ou recorreremos a unha visión moito máis institucional, etc. pois dende unha ou outra perspectiva e definición, a estrutura será totalmente diferente e marcará o desenvolvemento das seguintes fases.

Fase 2) Traballo de campo e elaboración dunha D.A.F.O. do noso sistema adaptado.- En función de a quen y en que modo vaia dirixido o plan de incentivos hai que determinar quen queda fóra deste alcance e por que.

Nesta fase é necesario coñecer perfectamente a situación da que partimos (económica, socio-política, legal, etc), valorar con que medios económicos e non económicos contamos 
para soster o devandito programa, coñecer cales son as necesidades ou prioridades dos traballadores aos que vai dirixido, a re-avaliación dos criterios establecidos en etapas anteriores e os seus resultados para coñecer erros e éxitos de experiencias previas.

A parametrización axeitada das nosas debilidades, ameazas, fortalezas e oportunidades como sistema, determinarán o éxito ou fracaso do plan.

Fase 3) Selección dos incentivos e do método de medición a utilizar.- É fundamental saber claramente que tipos de incentivos influirán no persoal en maior medida ou con maior rapidez, e cales malia seren máis lentos na súa efectividade, son eficaces e imprescindibles. Coñecer cales serían, a priori, aceptados dentro da organización e cales requirirían un consenso maior. Esta fase implica tamén o deseño de como se deberían dar a coñecer os incentivos definidos e de como se instaurará o plan de comunicación dos incentivos adoptados para que estes cheguen a todos os traballadores de forma clara e precisa.

Fase 4) Avaliación e revisión dos resultados.- Tan importante como deseñar e aplicar, é avaliar e medir. Polo tanto, esta fase implica a definición da medición de incentivos, así como definir quen terá encomendada a súa aplicación, revisión e medición.

Débese determinar cal será o tempo de aplicación e de medición de incentivos e débese contemplar se son ou non axeitados os sistemas de medición empregados ou se, pola contra, xorden deficiencias a corrixir nun futuro deseño.

Por suposto, o custo e tempo de medición deben ser equilibrados conforme os nosos recursos.

Fase 5) Aplicación de medidas correctoras.- Un bo plan de incentivos debe introducir no caso de que sexan necesarias, as medidas de corrección en positivo e en negativo dos incentivos deseñados.

Do mesmo modo debe contemplar se foi suficiente a información aplicada e utilizada, ou se foi detectado algún erro ou carencia na súa análise e como corrixilo no caso de que apareza.

Un bo plan debe deixar aberta a vía de posibles imprevistos e como atallalos e implantalos no caso que sexa necesario.

Fase 6) Comunicación dos resultados a todos os implicados no sistema baixo as premisas de fluidez e transparencia.

Débese establecer un método de información axeitado e transparente tanto do plan a implantar como dos resultados obtidos.

Por todo iso debemos falar de "deseño de incentivos" como unha campaña continua, calculada, programada, adaptada, aceptada e medida, onde todos os implicados formen parte do plan inicial, con independencia de que finalmente reciban ou non, parte deses incentivos en función dos seus resultados. Daí que sexa tan importante que o plan defina uns obxectivos claros e susceptibles de medición, pois, polo contrario, entraremos na espiral de desequilibrio e falta de equidade.

\section{CONCLUSIÓNS}

Resumindo todo o analizado e descrito nalgunhas conclusións finais diríamos que:

1) Os incentivos sen dúbida forman parte de todos ou case todos os sistemas produtivos mesmo se o sistema sanitario é público ou privado.

2) Non existe unha solución única na análise dos incentivos polo que debemos facer un traxe a medida no deseño dun plan de incentivos para a nosa entidade ou institución. 
Debemos polo tanto coñecer as características do sistema sanitario e da nosa entidade para facer o deseño o máis axeitado posible.

3) Existe unha variada, complexa e moi diversa bibliografía sobre os estudos de inventivos con conclusións moi diversas e sen un acordo común unánime.

4) Debemos abrirnos a explorar todas as posibilidades de incentivos legais e éticos posibles, así como coñecer e descartar aqueles que sexan consideramos ilícitos ou perversos para o individuo e/ ou para o sistema. Para iso é necesario coñecer todos os incentivos posibles aplicados ou non, positivos e negativos.

5) Finalmente deseñar un plan de incentivos eficaz e a medida para o sistema que nos ocupa.

\section{ANEXO.- BIBLIOGRAFÍA}

\section{1.- Normativa Xurídica e outra regulación}

- Lei 44/ 2003, do 28 de maio, de Cohesión e Calidade do Sistema Nacional de Saúde

- Lei 55/ 2003, do 16 de decembro, do Estatuto Marco do Persoal Estatutario dos servizos de saúde.

- Comité central de ética e Deontoloxía da OMC, informe sobre a diminución das retribucións económicas correspondentes á produtividade por cumprimiento de obxectivos (maio de 2007).

\section{2.- Outros enlaces de interese}

- A ética en relación coa industria farmacéutica. Enquisa a médicos de familia en Cataluña. Atención primaria 2004;34 81): 6-12

- Resumo do debate organizado pola Fundación Ciencias da Saúde e SESCAM.

Revista Eidon número 36; xaneiro -abril 2012.

\section{3.- Bibliografía}

- Álvarez Baza MC. Motivación Laboral de un servicio de urgencias hospitalario. Enfermería Clínica 2003; 13 (1): 16-25

- Casajuana J, Clavería A, Dominguez M. et al. Propuestas para la transformación de la atención primaria de Galicia. Pontevedra: Subdirección General de Calidad y programas asistenciales. Servicio Gallego de Salud. Escuela Gallega de Administración Sanitaria (FEGAS); 2009.

- Eirea C, Ortún Rubio V. Incentivos financieros en la mejora de la calidad asistencial. Informe SESPAS 2012. Gaceta Sanitaria 2012; 26(S): 102-106

-Diaz Ojeda E, Navarro P, Prados S. Sistema Nacional de Salud: La retribución variable. Revista Administración Sanitaria. 2005; 3: 205-235.

-Hongoro C, Normand C. Health workers : building and motivating the workforce. In D. Jamison er al. (eds), Disease Control Priorities in Developing Countries, 2nd edn, Oxford, New York, pp. 1, 309-1,322

- Iglesias Clemente J. La carrera profesional en el marco de un sistema de incentivos. Siete años después: los riesgos de un modelo burocrático. Atención primaria 2004; 34 (5): 219221 
- Ortún V. Los incentivos para la mejora de la calidad de los servicios de salud. Rev. Calidad Asistencial. 2007; 22: 1-6.

-Peirós S, Bernal-Delgado E. ¿A qué incentivos responde la utilización hospitalaria del Sistema Nacional de Salud? Gaceta Sanitaria 2006; 20 (Suplemento 1): 110.

- Peiró S, García-Altés A. Posibilidades y limitaciones de la gestión por resultados de salud, el pago por objetivos y el redireccionamiento de los incentivos. Gaceta sanitaria. 2008; 22 Sup 1: 143-155.

- Plaza G. motivación y política de incentivos para médicos dedicados a la atención hospitalaria del Sistema nacional de Salud: opinión de un grupo de expertos. Revista de calidad asistencial 2001; 16 (8): 739-744

- Prieto Orzanco A, Planes Magriñá A, Vázquez Díaz JR: Ética y estética de los sistemas de incentivos económicos directos: encrucijadas entre la eficiencia y la equidad en la practica clínica. Atención primaria 2000; 26 (4): 201-202.

-Valor J, Ribera J. Gestión de la empresa hospitalaria. Documento de investigación IESE Business School. Di no 199-Octubre, 1990.

Revista Galega de Economía: http:// www.usc.es/ revistas/ index.php/ rge

http:// www.usc.es/ econo/ RGE/ benvidag.htm 